\title{
EXTERNAL STENTING REDUCES EARLY MEDIAL AND NEOINTIMAL THICKENING IN A PIG MODEL OF ARTERIOVENOUS BYPASS GRAFTING
}

Gianni D. Angelini, FRCS

Mohammad Bashar Izzat, FRCS

Alan J. Bryan, FRCS

Andrew C. Newby, PhD
The long-term clinical success of coronary artery bypass grafting with autologous saphenous vein is limited by progressive medial and neointimal thickening in the graft and superimposed atherosclerosis. We sought to reduce wall thickening by applying an external stent to experimental grafts in pigs. The diameter of the stent was designed to allow unrestricted initial expansion of the vein in response to arterial pressure and the stent material was highly porous so as to minimize advential disruption. Four weeks after graft implantation, stented grafts had a larger lumen (11.2 \pm 6.2 [standard deviation] $\mathrm{mm}^{2}$ versus $7.6 \pm 3.4 \mathrm{~mm}^{2}, p<0.05, n=9$ ) and an almost fourfold thinner media $(0.14 \pm 0.08$ versus $0.49 \pm 0.22, p<0.001)$ and neointima $(0.10 \pm 0.07$ versus $0.35 \pm 0.24, p<0.001)$ than paired unstented grafts in the same animals. Cell proliferation was also greatly reduced by stenting in the neointimal and medial layers. The stenting procedure devised here is readily applicable to clinical coronary bypass grafts. (J Thorac Cardiovasc Surg 1996;112:79-84)
$\mathrm{B}_{\mathrm{s}}^{\mathrm{y}}$ ypass of stenotic coronary arteries with autologous saphenous vein has become an established treatment for end-stage atherosclerotic disease, with more than 400,000 procedures done in the United States alone each year. ${ }^{1}$ The long-term clinical success of coronary bypass grafting, however, is limited by occlusion of up to $50 \%$ of grafts within 10 years. $^{2-4}$ Late occlusion results from progressive medial and neointimal thickening with superimposed vein graft atherosclerosis. Apart from therapy to lower lipid levels, ${ }^{5}$ no pharmacologic or surgical intervention has been shown conclusively to influence the evolution of these changes either in man or in experimental models.

Recent work has established that migration and proliferation of vascular smooth muscle cells in response to endogenously generated growth factors underlies graft wall thickening. ${ }^{6-8}$ Growth factor

From the Bristol Heart Institute, University of Bristol, Bristol, United Kingdom.

Supported by grants from the British Heart Foundation and The Garfield Weston Trust.

Received for publication May 24, 1995; accepted for publication August 28, 1995.

Address for reprints: G. D. Angelini, FRCS, British Heart Foundation, Professor of Cardiac Surgery, Department of Cardiac Surgery, University of Bristol, Bristol BS2 $8 \mathrm{HW}$, United Kingdom.

Copyright (C) 1996 by Mosby-Year Book, Inc.

$0022-5223 / 96 \$ 5.00+0 \quad \mathbf{1 2} / \mathbf{1} / \mathbf{6 8 9 0 7}$ production may be stimulated by increased wall stress, ${ }^{9}$ hence placement of a restrictive external stent around vein grafts reduces total wall thickening. ${ }^{10,11}$ This, however, also promotes neointima formation leading to an overall reduction in luminal size ${ }^{10,11}$ possibly as a result of disruption of the vasa vasorum and resulting hypoxia. ${ }^{12}$

We investigated here the effect of a highly porous, nonrestrictive external polyester stent (Fig. 1) on luminal size and on the degree of medial and intimal thickening and cell proliferation in a pig saphenous vein graft model. ${ }^{13}$ Four weeks after implantation, we found that stented grafts had a larger lumen and dramatically reduced wall thickening compared with unstented grafts.

\section{Material and methods}

Studies were done with "white race" pigs ( $n=9$, weight 25 to $30 \mathrm{~kg}$ ), which received humane care according to the Home Office Animals (Scientific Procedures) Act 1986 (HMSO 1990). Animals were subjected to premedication, anesthesia, and autologous saphenous vein into common carotid artery bypass grafting by a modification of the method described previously. ${ }^{14}$ In brief, segments of saphenous vein were dissected, rinsed in iso-osmotic sodium chloride solution $\left(0.9 \mathrm{gm} \cdot \mathrm{L}^{-1}\right)$ containing 2 $\mathrm{IU} / \mathrm{ml}$ heparin and $50 \mu \mathrm{g} / \mathrm{ml}$ glyceryl trinitrate, and stored in the same solution at room temperature $\left(23^{\circ} \mathrm{C}\right)$ until needed. Both common carotid arteries of the pigs were exposed. A $3 \mathrm{~cm}$ segment of one artery at a time was removed and replaced with a segment of saphenous vein cut to allow implantation without longitudinal stretching. 


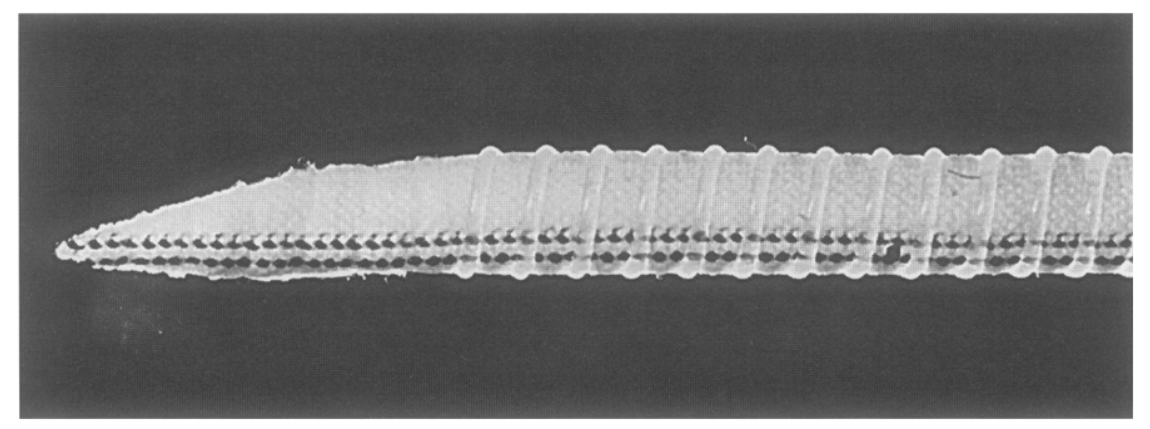

Fig. 1. Vascutek graft stent.

Anastomoses were conducted end-to-end with reversed vein, beveled at 45 degrees, with continuous 7-0 Prolene polypropylene sutures (Ethicon, Inc., Somerville, N.J.). ${ }^{14}$ Proximal anastomoses were always done first; in the case of stented grafts the vein segments were passed through the stent before the distal anastomosis was completed.

The stent (Fig. 1) comprised a continuous $6 \mathrm{~mm}$ diameter VP1200 polyester locknit tube externally supported with helically wound $0.8 \mathrm{~mm}$ polypropylene (gift of Vascutek Ltd, Inchinnan, Renfrewshire, United Kingdom). The stent was cut to a slightly greater length than the graft and held in position by two single 7-0 Prolene polypropylene stitches placed in the adventitia of the artery at each end. Each animal received a stented graft on one side and a control (unstented) graft on the opposite side. The entire procedure took 50 minutes with the order of implantation of stented and unstented grafts randomized among pigs. The use of the distal or proximal portions of the veins for stented or unstented grafts was also randomized.

The animals were allowed to recover and fed a normal chow diet for 4 weeks. Grafts were then removed, pressure fixed ex vivo at $100 \mathrm{~mm} \mathrm{Hg}$ for 10 minutes with the use of $10 \%$ buffered formal saline solution, post-fixed in the same solution for approximately 24 hours, and then processed for wax embedding. Transverse $(5 \mu \mathrm{m})$ sections were cut at four levels approximately $0.75 \mathrm{~mm}$ apart, mounted on glass slides, stained with alcian blue Miller's elastic van Gieson stain, and examined under a light microscope. Vessel wall dimensions were measured by computer-aided planimentry (MicroScale TM/TC image analysis system, Digithurst Ltd, Royston, Herts, United Kingdom), as described previously. ${ }^{13}$ In brief, luminal, intimal, and medial perimeters and areas were computed with use of the luminal boundary and internal and external elastic laminae as delimiters, and mean values were then calculated for all sections from the same graft. Average intimal, medial, and vessel wall thicknesses were derived from the area and perimeter data. ${ }^{13}$

Furthermore, proliferating cell nuclear antigen was detected in the sections by immunocytochemistry as described previously. ${ }^{15}$ Briefly, we used a primary monoclonal antibody (PC10, Dako Ltd, High Wycombe, Bucks, United Kingdom) at a 1/100 dilution. This was followed by a 1/50 dilution of biotinylated anti-mouse immunoglobulin $\mathrm{G}$ (Dako) and avidin-biotin-peroxidase conjugate (Dako) according to the manufacturer's instructions. Sections were counterstained with Harris' hematoxylin stain. Total number of cells and number of strongly positive cells were counted in both intima and media in five microscopic fields per section with a $\times 40$ objective.

Statistical analysis. Values are shown as the mean plus or minus the standard deviation (SD). Significance between groups was established with the Mann-Whitney U test, and data were considered significant if the $p$ value was equal to or less than 0.05 .

\section{Results}

The luminal diameter of pig saphenous vein measured by ultrasonography in situ before implantation was $1.6 \pm 0.3 \mathrm{~mm}$ (SD, $n=9$ ). Immediately after grafting to the common carotid artery, unstented veins increased in diameter to $3.6 \pm 0.6 \mathrm{~mm}$. Placement of a $6 \mathrm{~mm}$ diameter porous polyester stent (Fig. 1) around grafts to the contralateral artery had no effect on the diameter of the grafts (also $3.6 \pm 0.6 \mathrm{~mm}$ ) as measured by ultrasonography.

All grafts, whether stented or not, were patent 4 weeks after implantation. As illustrated in Fig. 2 and summarized in Table I, stented and unstented grafts had a similar total (lumen plus wall) cross-sectional area that was approximately four times greater than that of the original vein. This confirmed that the stent allowed expansion of the graft in response to arterial pressure. Unstented grafts showed an increase in luminal area compared with that of ungrafted vein. Unstented grafts also showed medial enlargement, fragmentation of the internal elastic lamina, and development of a neointima (Fig. 2, Table I), in agreement with previous observations. ${ }^{13}$ Stented grafts had a significantly greater final luminal area than unstented grafts (Table I). There was no medial enlargement compared with ungrafted vein, and neointima formation was dramatically reduced almost fourfold compared with that in unstented grafts (Fig. 2, Table I). As a result, the 

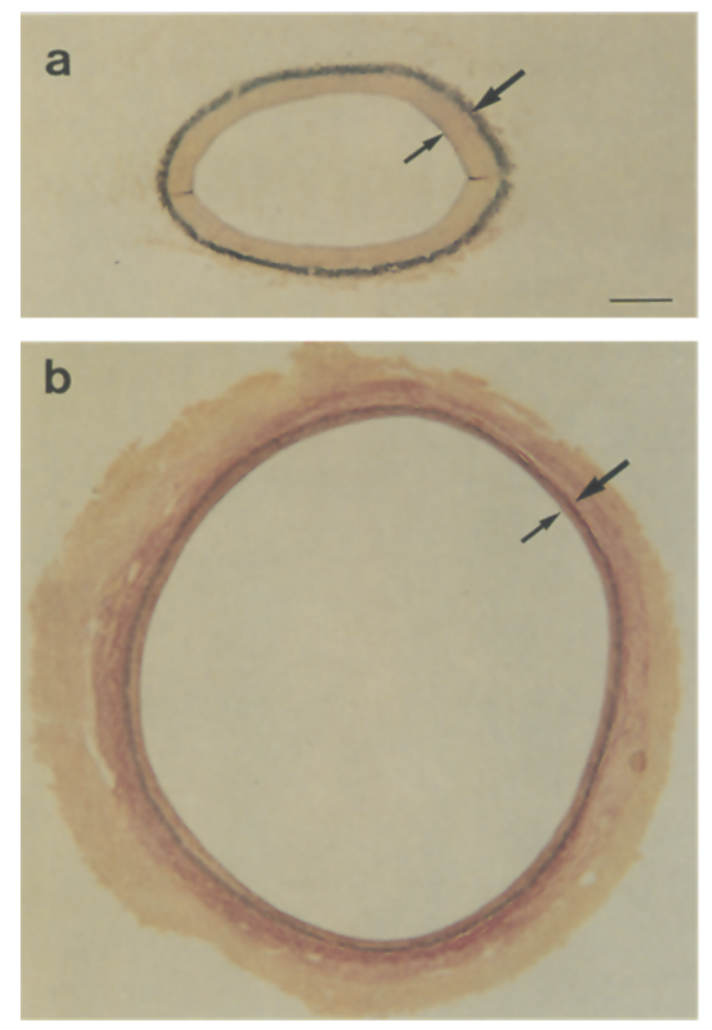

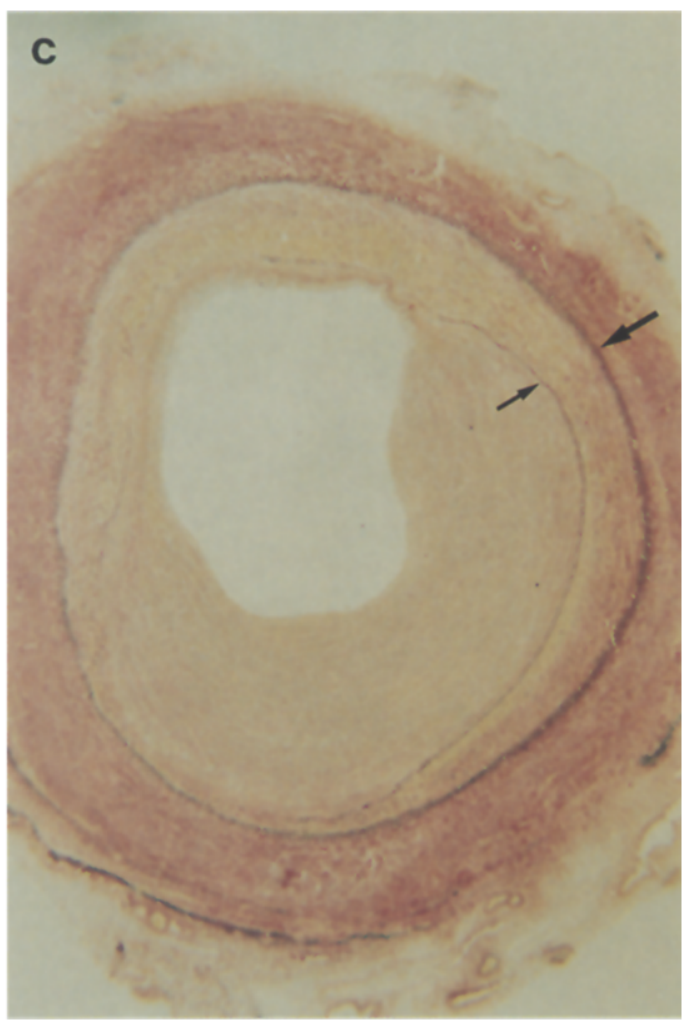

Fig. 2. Histologic appearance of ungrafted saphenous vein (a), representative stented graft (b) (stent material removed before wax embedding), and representative unstented graft (c). Small arrows indicate position of internal elastic lamina and large arrows indicate external elastic lamina. Scale bar relates to all panels and represents $0.5 \mathrm{~mm}$.

encroachment of the intima into the lumen was reduced by stenting from $33 \%$ to $13 \%$ (Fig. 2 , Table I).

The presence of cells progressing through the cell cycle was detected by immunocytochemistry for proliferating cell nuclear antigen (PCNA). ${ }^{15,16}$ PCNA-positive cells were rarely detected in ungrafted vein but were abundant in the media and the most luminal aspect of the neointima of unstented grafts (Fig. 3). For quantification of PCNA labeling, the total number and the number of PCNA-positive cells were counted in both the intima and the media in five microscopic fields of view with a Leica Laborlux S microscope (Leica Instruments $\mathrm{GmbH}$, Nussloch, Germany) and $\times 40$ objective. The number of PCNA-positive cells was expressed as a proportion of the total cell number (PCNA index). The medial PCNA index was reduced by stenting from $21 \% \pm 4 \%$ to $2.4 \% \pm 2.2 \%(p<0.001)$. The neointimal PCNA index was also reduced by stenting from $24 \% \pm 4 \%$ to $7 \% \pm 3 \%(p<0.01)$. PCNA labeling in the neoadventitia was observed in both stented and unstented grafts (Fig. 3). The presence of microvessels penetrating the media of stented grafts can also be noted in Fig. 3. There were endothelial cells lining these vessels, as confirmed by staining for Dolichos bifloros lectin (results not shown). Such vessels were absent from the media of ungrafted vein or unstented grafts (Fig. 3).

\section{Discussion}

Morphologic and clinical studies of human vein grafts (reviewed in references 17 through 20) demonstrate three phases in the response of vein to arterial implantation. In the first hours to days, mural or occlusive thrombosis can occur as a result of endothelial denudation and rheologic disturbance. Over the next months, there is progressive medial and neointimal thickening as a result of the migration and proliferation of vascular smooth muscle cells. In extreme cases, this can compromise flow directly or promote thrombotic occlusion. During 

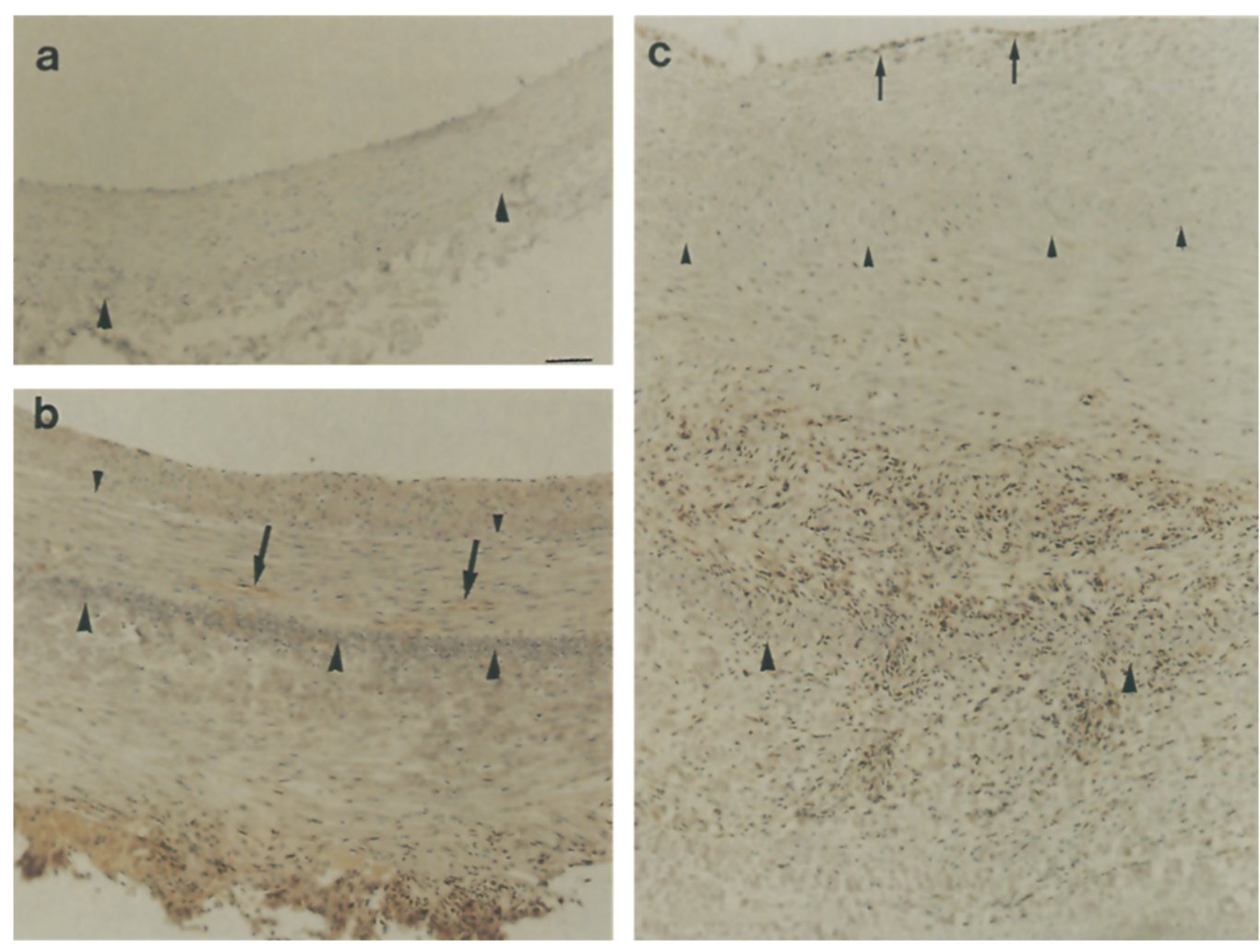

Fig. 3. Immunocytochemistry for PCNA in ungrafted vein (a), representative stented graft (b) (note presence of vasa vasorum indicated by large arrows), and representative unstented graft (c) (note presence of PCNA-positive cells in neointima close to luminal surface indicated by small arrows). Small triangles indicate position of internal elastic lamina and large triangles indicate external elastic lamina. Scale bar relates to all panels and represents $0.5 \mathrm{~mm}$.

Table I. Dimensions of saphenous vein and unstented and stented grafts

\begin{tabular}{lcccc}
\hline \multicolumn{1}{c}{ Parameter } & Ungrafted vein & Unstented graft & Stented graft & $p$ Value \\
\hline Total cross-sectional area $\left(\mathrm{mm}^{2}\right)$ & $3.7 \pm 1.2$ & $18.0 \pm 5.8$ & $13.9 \pm 5.9$ & 0.1 \\
Luminal area $\left(\mathrm{mm}^{2}\right)$ & $2.5 \pm 1.2$ & $7.6 \pm 3.4$ & $11.2 \pm 6.2$ & $<0.05$ \\
Medial area $\left(\mathrm{mm}^{2}\right)$ & $1.2 \pm 0.9$ & $6.55 \pm 2.62$ & $1.62 \pm 0.52$ & $<0.001$ \\
Intimal area $\left(\mathrm{mm}^{2}\right)$ & 0 & $3.84 \pm 3.3$ & $1.06 \pm 0.37$ & $<0.001$ \\
Intimal encroachment $(\%)$ & 0 & $33.2 \pm 19.1$ & $13.3 \pm 13.4$ & $<0.005$ \\
Total wall thickness (mm) & $0.13 \pm 0.06$ & $0.85 \pm 0.38$ & $0.25 \pm 0.14$ & $<0.001$ \\
Medial thickness (mm) & $0.13 \pm 0.06$ & $0.49 \pm 0.22$ & $0.14 \pm 0.08$ & $<0.001$ \\
Intimal thickness (mm) & 0 & $0.35 \pm 0.24$ & $0.10 \pm 0.07$ & $<0.001$
\end{tabular}

Results for stented versus unstented grafts were compared by Mann-Whitney $U$ test. Values are expressed as mean plus or minus standard deviation.

the following years, there is a tendency for atheroma to occur superimposed on the thickened intima and this is associated with an increasing rate of graft occlusion between 5 and 10 years after implantation. $^{2-4}$ Experimental grafts in dogs, rabbits, nonhuman primates, and pigs $^{14,21-24}$ have reproduced many aspects of the human pathologic process. Progressive medial and neointimal thickening occurs and hypercholesterolemia promotes deposition of lipoproteins in the grafts. ${ }^{23}$

Early thrombotic occlusions can be reduced in both clinical and experimental studies by a variety of 
antiplatelet agents ${ }^{25}$ and also by avoidance of incidental vessel wall injury during surgical preparation and implantation. ${ }^{14,26}$ Both platelet activation and tissue injury have also been implicated in the pathogenesis of neointimal thickening. $19,20,27-30$ However, neither antiplatelet therapy nor avoidance of surgical preparative injury has been shown conclusively to eliminate medial and neointimal thickening either in experimental models or in human vein grafts. ${ }^{26}$ It has recently been shown that grafting stimulates the production of endogenous growth factors from pig saphenous vein, ${ }^{8}$ which may explain the platelet-independence of wall thickening. Vessel wall thickening may then be regarded as an intrinsic adaptation of the vein to arterial pressure. Indeed, Zwolak, Adams, and Clowes ${ }^{9}$ noted that the ratio of luminal radius to wall thickness in grafts tends to adapt to the same value as that in the grafted artery, which suggests that wall thickening occurs to normalize tangential wall stress. This hypothesis is partly borne out by two studies that showed that restrictive external stents reduce overall graft wall thickening. ${ }^{10,11}$ However, although such stenting reduces medial thickening, it promotes neointimal thickening and leads to a reduction rather than an increase in final luminal size. Enhanced neointima formation in such stented grafts may result from reduction of fluid flux, thereby increasing the effective concentration of endogenously produced mitogens. Another possibility is that adventitia disruption leads to vessel wall hypoxia. ${ }^{12,31}$ Hence ligating the femoral artery vasa vasorum in the pig femoral artery or placing a silicone-rubber collar around the rabbit carotid artery causes a rapid neointimal thickening that can be avoided if adventitial regrowth is encouraged. ${ }^{12,31}$

In this study, a highly porous material was used so as to minimize any effects on fluid flux and permit the unhindered growth of a new adventitia. The size of the stent was chosen to allow unrestricted expansion of the graft in initial response to arterial pressure. The stent then became incorporated into the neoadventitia whereupon it presumably began to bear a proportion of the wall stress. Reduction in the tangential wall stress borne by the graft might then explain why medial thickening was abolished and neointimal formation was dramatically reduced, leading to an increase in final luminal size. Another possibility, supported by the observation of vasa vasorum penetrating the media of stented grafts, is that modification of the structure of the neoadventitia led to improved fluid flux or less hypoxia. The
PCNA data imply that reduction in the rate of smooth muscle cell proliferation contributed substantially to the reduction in wall thickening.

The type of stenting material and the procedure used here are readily applicable to human saphenous vein grafts. An increase in final luminal size in stented grafts would be expected to favor unrestricted flow and hence reduce thrombotic occlusions. Decreased wall thickness also implies a reduced risk of lipoprotein and macrophage accumulation and hence less vein graft atheroma. The impact of this kind of stent on wall thickness and patency needs now to be tested directly in clinical studies.

\section{REFERENCES}

1. Marwick $\mathrm{C}$. Coronary bypass grafting economics, including rehabilitation. Curr Opin Cardiol 1994;9:635-40.

2. Campeau L, Enjalbert M, Lesperance J, Vaislic C, Grondin $\mathrm{CM}$, Bourassa MG. Atherosclerosis and late closure of saphenous vein grafts: sequential angiographic studies 2 weeks, 1 year, 5 to 7 years and 10 to 12 years after surgery. Circulation 1983;68 (Suppl):II1-7.

3. Grondin CM, Campeau L, Lesperance J, Enjalbert M, Bourassa MG. Comparison of late changes in internal mammary artery and saphenous veins in two consecutive series of patients 10 years after operation. Circulation 1984;70(Suppl): 1208-12.

4. Lytle BW, Loop FD, Cosgrove DM, Ratliff NB, Easly K, Taylor PC. Long term (5 to 12 years) serial studies of internal mammary artery and saphenous vein coronary bypass grafts. J Thorac Cardiovasc Surg 1985;89:248-58.

5. Blankenhorn DH, Nessim SA, Johnson RL, Sanmarco ME, Azen SP, Cashin-Hemphill L. Beneficial effect of combined colestipol-niacin therapy on coronary atherosclerosis and coronary venous bypass grafts. JAMA 1987;257:3233-40.

6. Golden MA, Au YPT, Kenagy RD, Clowes AW. Growth factor gene expression by intimal cells in healing polytetrafluoroethylene grafts. J Vasc Surg 1990;11:580-5.

7. Golden MA, Au YPT, Kirkman TR, et al. Platelet-derived growth factor activity and mRNA expression in healing vascular grafts in baboons. J Clin Invest 1991;87:406-14.

8. Francis SE, Hunter S, Holt CM, et al. Release of platelet derived growth factor activity from arteriovenous bypass grafts. J Thorac Cardiovasc Surg 1994;108:540-8.

9. Zwolak RM, Adams MC, Clowes AW. Kinetics of vein graft hyperplasia: association with tangential stress. J Vasc Surg 1987;5:126-36.

10. Kohler T, Kirkman TR, Clowes AW. The effect of rigid external support on vein graft adaptation to the arterial circulation. J Vase Surg 1989;9:277-85.

11. Violaris A, Newby AC, Angelini GD. Effect of external stenting on wall thickening in arteriovenous bypass grafts. Ann Thorac Surg 1993;55:667-71.

12. Barker SGE, Talbert A, Cottam S, Baskerville PA, Martin JF. Arterial intimal hyperplasia after occlusion of the adventitial vasa vasorum in the pig. Arterioscler Thromb 1993;13: 70-7.

13. Angelini GD, Bryan AJ, Williams HMJ, et al. Time course of. medial and intimal thickening in pig arteriovenous bypass grafts: 
relationship to endothelial injury and cholesterol accumulation. J Thorac Cardiovasc Surg 1992;103:1093-103.

14. Angelini GD, Bryan AJ, Williams HMJ, Morgan R, Newby AC. Distention promotes platelet and leukocyte adhesion and reduces short-term patency in pig arteriovenous bypass grafts. J Thorac Cardiovase Surg 1990;99:433-9.

15. Galand P, Degraef C. Cyclin/PCNA immunostaining as an alternative to tritiated thymidine pulse labelling for marking S-phase cells in paraffin sections from animal and human tissues. Cell Tissue Kinet 1989;22:383-92.

16. Hall PA, Levison DA, Woods AL, et al. Proliferating cell nuclear antigen (PCNA) immunolocalization in paraffin sections: an index of cell proliferation with evidence of deregulated expression in some neoplasms. J Pathol 1990;162:285-94.

17. Dilley RJ, McGeachie JK, Prendergast FJ. A review of the histological changes in vein to artery grafts, with particular reference to intimal hyperplasia. Arch Surg 1988;123: 691-6.

18. Angelini GD, Newby AC. The future of saphenous vein as a coronary artery bypass conduit. Eur Heart J 1989;10:273-80.

19. Fuster V, Badimon L, Badimon JJ, Chesebro JH. Mechanisms of disease: the pathogenesis of coronary artery disease and the acute coronary syndromes (first of two parts). N Engl J Med 1992;326:242-50.

20. Fuster V, Badimon L, Badimon JJ, Chesebro JH. Mechanisms of disease: the pathogenesis of coronary artery disease and the acute coronary syndromes (second of two parts). N Engl J Med 1992;326:310-8.

21. Fonkalsrud EW, Sanchez M, Zerubavel R. Morphological evaluation of canine autogenous vein grafts in the arterial circulation. Surgery 1978;84:253-64.

22. Gershlick AH, Sydercombe Court YD, Murday AJ, Lewis T, Mills PG. Platelet function is altered by autogenous vein grafts in the early postoperative months. Cardiovasc Res 1984;18:119-25.

23. Bocrboom LE, Olinger GN, Tie-Zhu L, Rodriguez ER, Ferrans VJ, Kissebah AH. Histologic, morphometric, and biochemical evolution of vein bypass grafts in a nonhuman primate model. J Thorac Cardiovasc Surg 1990;99:97-106.

24. Angelini GD, Soyombo AA, Newby AC. Smooth muscle cell proliferation in response to injury in an organ culture of human saphenous vein. Eur J Vasc Surg 1991;5:5-12.

25. Israel DH, Adams PC, Stein B, Chesebro JH, Fuster V. Anti-thrombotic therapy in the coronary vein graft patient. Clin Cardiol 1991;14:283-95.

26. LoGerfo FW, Quist WC, Cantelmo NL, Haudenschild CC. Integrity of vein grafts as a function of initial intimal and medial preservation. Circulation 1983;68(Suppl):II117-24.

27. Metke MP, Lie JT, Fuster V, Josa M, Kaye MP. Reduction of intimal thickening in canine coronary bypass grafts with dipyridamole and aspirin. Am J Cardiol 1979;43:1144-8.

28. Lindner V, Lappi DA, Baird A, Majack RA, Reidy MA. Role of basic fibroblast growth factor in vascular lesion formation. Circ Res 1991;68:106-13.

29. Soyombo AA, Angelini GD, Bryan AJ, Newby AC. Surgical preparation induces injury and promotes smooth muscle cell proliferation in a culture of human saphenous vein. Cardiovasc Res 1993;27:1961-7.

30. Soyombo AA, Angelini GD, Newby AC. Intima formation is promoted by surgical preparation and inhibited by cyclic nucleotides in human saphenous vein organ cultures. J Thorac Cardiovasc Surg 1995;109:2-12.

31. Barker SGE, Tilling LC, Miller GC, et al. The adventitia and atherogenesis: removal initiates intimal proliferation in the rabbit which regresses on generation of a "neoadventitia." Atheroselerosis 1994;105:131-44. 